\title{
Deposição do herbicida 2,4-D Amina com diferentes volumes e pontas de pulverização em plantas infestantes ${ }^{1}$
}

\author{
Weed deposition of 2,4-D Amine herbicide applied with different spray volumes and \\ nozzles
}

\author{
Lélio Augusto de Souza ${ }^{2 *}$, João Paulo Arantes Rodrigues da Cunha ${ }^{3}$ e Luiz Alfredo Pavanin ${ }^{4}$
}

\begin{abstract}
Resumo - A tecnologia de aplicação de fitossanitários visa à colocação uniforme do produto no alvo, com mínimas perdas para o solo e por deriva. Desta forma, os objetivos deste trabalho foram estudar a deposição do herbicida 2,4-D Amina, aplicado em diferentes condições operacionais, em plantas infestantes e comparar as metodologias de estudo de deposição baseadas na detecção do ingrediente ativo por cromatografia líquida de alta eficiência (HPLC) e de um traçador adicionado à calda por espectrofotometria. $\mathrm{O}$ experimento foi conduzido em delineamento de blocos casualizados, com seis tratamentos e quatro repetições, dispostos em esquema fatorial 3 x 2: três pontas de pulverização (ponta de jato plano duplo de pré-orifício, ponta de jato plano defletor e ponta de jato plano defletor com indução de ar) e dois volumes de aplicação ( 80 e $\left.130 \mathrm{~L} \mathrm{ha}^{-1}\right)$. Foi realizado o estudo de deposição de calda nas plantas infestantes, perdas para o solo e perdas por exoderiva. Concluiu-se que houve baixa correlação entre os dados de deposição na folhagem das plantas infestantes obtidos com as duas metodologias. Pontas que produzem gotas grossas podem ser utilizadas na dessecação, sem comprometer a cobertura do alvo. Quanto à deposição junto ao solo, a correlação foi significativa. Pontas de jato plano defletor com indução de ar promoveram maior perda de herbicida para o solo. Não foi possível detectar perdas por exoderiva pelas metodologias empregadas.
\end{abstract}

Palavras-chave - Pesticidas - Aplicação. Defensivos vegetais. Equipamentos de pulverização. Pesticidas.

\begin{abstract}
Pesticide spray technology aims the uniform deposition of products in the target, with minimal losses to the soil or drift. Thus, the objectives of this study were to evaluate the 2,4-D Amine deposition, applied on weeds in different operational conditions, and compare two different measurement techniques: analysis of 2,4-D by high performance liquid chromatography and tracer analysis using spectrophotometry. The experimental design was randomized blocks with six treatments and four replications, as a 3 x 2 factorial model: three spray nozzles (drift guard twin flat-fan, turbo flat-fan and air induction turbo flatfan) and two spray volumes ( $80 \mathrm{~L} \mathrm{ha}^{-1}$ and $\left.130 \mathrm{~L} \mathrm{ha}^{-1}\right)$. The spray process was studied by the deposition on the weeds, losses to the soil, and losses by exo-drift. According to the results, it can be concluded that the correlation coefficient between the results of weed deposition from the two methodologies was low. Coarse droplets can be used for weed desiccation, without compromising target coverage. The correlation was significant to the soil loss. Air induction turbo flat-fan nozzles promoted greater herbicide loss to the soil. Drift was not detected with the methodologies employed.
\end{abstract}

Key words - Pesticides - Application. Phytosanitary. Spray equipments. Pesticides.

\footnotetext{
*Autor para correspondência

${ }^{1}$ Recebido para publicação em 28/01/2011; aprovado em 17/06/2011

Parte da Dissertação de Mestrado do primeiro autor apresentada ao Programa de Pós-Graduação em Agronomia/UFU

${ }^{2}$ Instituto de Ciências Agrárias, Universidade Federal de Uberlândia/UFU, Campus Umuarama, Uberlândia-MG, Brasil, Caixa Postal 593, 38.400-902, lelioagro@terra.com.br

${ }^{3}$ Instituto de Ciências Agrárias, UFU, Bolsista CAPES, Uberlândia-MG, Brasil, jpcunha@iciag.ufu.br

${ }^{4}$ Instituto de Química, UFU, Uberlândia-MG, Brasil, pavanin@ufu.br
} 


\section{Introdução}

O controle de plantas infestantes por meio da utilização de herbicidas é uma prática de elevada importância para a obtenção de altos rendimentos na exploração agrícola. Contudo, seu êxito está ligado à correta tecnologia de aplicação. É necessário que ocorra boa deposição no alvo, como mínima perda por escorrimento e por exoderiva (CUNHA, 2008; SUGUISAWA et al., 2007). Muitas vezes, parte do produto aplicado perdese no ambiente, principalmente pela má qualidade da aplicação, sendo este um dos maiores problemas da agricultura moderna a ser superado (CUNHA et al., 2010; NUYTTENS et al., 2006; TSAI et al., 2005).

Além de estudar fatores inerentes às plantas infestantes a serem controladas, é imprescindível também estudar fatores inerentes à aplicação, como o tamanho e a densidade de gotas, as perdas para o solo e por deriva, o equipamento pulverizador, o volume de calda e as pontas de pulverização (SOUZA et al., 2007; VIANA et al., 2007).

Uma das formas de se obter maior deposição do ingrediente ativo sobre alvos biológicos é a seleção correta das pontas de pulverização. Essas pontas são os componentes mais significativos dos pulverizadores, afetando diretamente a eficiência do processo de aplicação de agroquímicos (NUYTTENS et al., 2007). Outra variável importante na aplicação é o volume de calda, sendo que, atualmente existe tendência em reduzir esse volume (BOLLER; MACHRY, 2007), de forma a aumentar a capacidade operacional dos pulverizadores e reduzir os custos de produção. Contudo, essa redução de volume requer otimização da tecnologia de aplicação para assegurar a manutenção da eficiência das aplicações.

O estudo de deposição de produtos fitossanitários tem sido feito por vários pesquisadores empregando diferentes metodologias (HEWITT, 2010). Contudo, segundo Palladini, Raetano e Velini (2005) são necessários mais estudos que permitam caracterizar e aumentar a precisão dessas metodologias. As metodologias utilizadas são, na maioria das vezes, imprecisas e de difícil execução (PINTO et al., 2007).

A cromatografia líquida de alta eficiência é a mais usada de todas as técnicas analíticas de separação e quantificação na indústria. As razões para a popularidade do método estão ligadas à sua sensibilidade e adaptação para determinações quantitativas acuradas, porém seu custo é elevado e, por vezes, envolve metodologias de extração complexas.

Com relação ao uso de traçadores, o primeiro passo importante refere-se a sua escolha. Ela deve levar em conta a estabilidade a luz solar, temperatura, armazenamento e pH, o nível de detecção, a toxicidade, a persistência e a solubilidade (PALLADINI et al., 2005). Em geral, são detectados por colorímetros, espectrofotômetros ou fluorímetros. Trata-se de uma metodologia mais simples, de menor custo em comparação à detecção do ingrediente ativo, contudo deve ser levada em conta a possibilidade da não representatividade dos dados em relação à aplicação do fitossanitário, o que requer mais estudos.

Desta forma, o objetivo deste trabalho foi estudar a deposição do herbicida 2,4-D Amina, aplicado em diferentes condições operacionais, em plantas infestantes e comparar as metodologias de estudo de deposição baseadas na detecção do ingrediente ativo por cromatografia líquida de alta eficiência (HPLC) e de um traçador adicionado à calda por espectrofotometria.

\section{Material e métodos}

O experimento de campo foi realizado na estação de pesquisa da Syngenta Seeds, localizada no município de Uberlândia-MG. A parte laboratorial, no Laboratório de Análise de Água do Instituto de Química e no Laboratório de Mecanização Agrícola do Instituto de Ciências Agrárias, ambos na Universidade Federal de Uberlândia.

Com intuito de avaliar o processo de aplicação de herbicida em dessecação de plantas infestantes, foi utilizado o ingrediente ativo 2,4-D (Produto comercial DMA $806 \mathrm{BR}^{\circledR}$, na concentração de $806 \mathrm{~g} \mathrm{~L}^{-1}$ de i.a.) na dose de $1 \mathrm{~L} \mathrm{ha}^{-1}$ de produto comercial, conforme recomendação do fabricante, tendo como referencial teórico a instalação futura da cultura do milho. A área utilizada para a aplicação estava em pousio há quatro meses, sendo o milho a cultura anterior.

Juntamente à calda de aplicação, foi adicionado também um traçador composto do corante alimentício Azul Brilhante (catalogado internacionalmente pela "Food, Drug \& Cosmetic" como FD\&C Blue n.1). O corante foi utilizado na dose de $300 \mathrm{~g} \mathrm{ha}^{-1}$ (ajustando-se a quantidade de corante adicionada ao tanque em função do volume de aplicação empregado), para ser detectado por absorbância em espectrofotometria.

O experimento foi conduzido no delineamento de blocos ao acaso, com seis tratamentos e quatro repetições, totalizando 24 parcelas, com área de $35 \mathrm{~m}^{2}(7 \times 5 \mathrm{~m})$, dispostos em esquema fatorial $3 \times 2$ : três pontas de pulverização e dois volumes de calda, conforme descrito na Tabela 1. A largura da parcela correspondeu à metade da barra do pulverizador, descontando-se a área referente à bitola do trator. Utilizou-se uma bordadura de dois metros entre parcelas para garantir a estabilização da pressão, com acionamento prévio do sistema, e da velocidade de trabalho.

Foi utilizado um pulverizador de barra hidráulico tratorizado montado, modelo Jacto AM-14, com barra de $14 \mathrm{~m}$, espaçamento entre bicos de $0,50 \mathrm{~m}$ e capacidade do tanque de $600 \mathrm{~L}$. A pressão de líquido empregada 
Tabela 1 - Descrição dos tratamentos avaliados

\begin{tabular}{clccc}
\hline \multirow{2}{*}{ Tratamento } & \multicolumn{1}{c}{ Ponta de pulverização } & $\begin{array}{c}\text { Volume de } \\
\text { calda }\left(\mathrm{L} \mathrm{ha}^{-1}\right)\end{array}$ & $\begin{array}{c}\text { Classificação do } \\
\text { tamanho de gota* }\end{array}$ & $\begin{array}{c}\text { Diâmetro de gotas } \\
\text { DMV }(\mu \mathrm{m}) *\end{array}$ \\
\cline { 2 - 5 } & & 80 & Média & 216 \\
2 & Jato plano duplo de pré-orifício - DGTJ60 11002 & 130 & Média & 216 \\
3 & Jato plano duplo de pré-orifício - DGTJ60 11002 & 80 & Grossa & 380 \\
4 & Jato plano defletor - TT 11002 & 130 & Grossa & 380 \\
5 & Jato plano defletor - TT 11002 & 80 & Extremamente grossa & 925 \\
6 & Jato plano defletor com indução de ar - TTI 11002 & 130 & Extremamente grossa & 925 \\
\hline
\end{tabular}

* Classificação do tamanho de gota e diâmetro da mediana volumétrica (DMV), segundo o fabricante, a $200 \mathrm{kPa}$ de pressão

foi de $207 \mathrm{kPa}$ e a velocidade de deslocamento, para o volume de aplicação de $80 \mathrm{~L} \mathrm{ha}^{-1}$, foi de $10 \mathrm{~km} \mathrm{~h}^{-1} \mathrm{e}$, para volume de $130 \mathrm{~L} \mathrm{ha}^{-1}$, de $6 \mathrm{~km} \mathrm{~h}^{-1}$.

Para avaliar o processo de aplicação do herbicida 2,4-D Amina, foi conduzido o estudo de deposição da calda nas plantas infestantes, perdas para o solo e perdas por exoderiva. Este estudo foi realizado por meio de duas metodologias distintas, buscando verificar a relação e concordância entre elas: análise direta do ingrediente ativo 2,4-D Amina (cromatografia líquida) e análise indireta por meio da quantificação do traçador adicionado à calda (espectrofotometria).

Após a aplicação do herbicida + corante, a avaliação da deposição foi realizada com a retirada das plantas infestantes de cada parcela. As plantas foram coletadas tendo como referência um quadrado de madeira medindo $0,20 \times 0,20 \mathrm{~m}$, lançado ao acaso duas vezes em cada parcela. Elas foram cortadas rente ao solo e acondicionadas em sacos plásticos. Às amostras para quantificação do traçador, foi adicionada água destilada e, às amostras para quantificação do ingrediente ativo, nada foi adicionado.

Posteriormente, as amostras foram levadas ao laboratório para extração e determinação da quantidade de ingrediente ativo depositado, por meio do método da cromatografia líquida de alta eficiência (High Performance Liquide Chromatography). Inicialmente, as amostras foram homogeneizadas manualmente, sendo retiradas $5 \mathrm{~g}$ para maceração, em presença de um volume de $25 \mathrm{~mL}$ de álcool metílico P.A. A amostra resultante foi, então, filtrada em papel filtro e armazenada a $2{ }^{\circ} \mathrm{C}$ para posterior quantificação.

A quantificação foi realizada em um HPLC com detector de UV-Vis, da marca Shimadzu. As condições cromatográficas para as análises foram as seguintes: a fase móvel utilizada foi acetonitrila/água $+0,1 \% \mathrm{H}_{3} \mathrm{PO}_{4}$, na proporção de $50 / 50 \mathrm{v} / \mathrm{v}$, com um fluxo de $1,4 \mathrm{~mL} \mathrm{~min}^{-1}$, forno a $30^{\circ} \mathrm{C}$, detecção na região do UV-Vis, no comprimento de onda $201 \mathrm{~nm}$ e coluna $\mathrm{C}_{18}$ com $15 \mathrm{~cm}$ de comprimento. Nestas condições, o herbicida apresentou tempo de retenção de 4,0 minutos.

A curva padrão foi confeccionada no intervalo de concentração $0,10 \mathrm{mg} \mathrm{L}^{-1} \mathrm{e} 2,50 \mathrm{mg} \mathrm{L}^{-1}$, em função da área apresentada no cromatograma. $\mathrm{O}$ coeficiente de correlação da curva foi de 0,99 . Obteve-se um limite de quantificação de $0,10 \mathrm{mg} \mathrm{L}^{-1}$ e um limite de detecção de $0,047 \mathrm{mg} \mathrm{L}^{-1}$.

A determinação do ingrediente ativo perdido para o solo foi realizada por meio da distribuição ao acaso de 4 lâminas de vidro $\left(37,24 \mathrm{~cm}^{2}\right)$ por parcela. Após a aplicação e secagem das lâminas, elas foram retiradas e armazenadas em sacos plásticos e levadas para o laboratório, onde foram lavadas com um volume de $25 \mathrm{~mL}$ de álcool metílico P.A., para extração e quantificação do produto presente, de forma semelhante à mencionada anteriormente.

Para a determinação da deriva, foram colocados a $5 \mathrm{~m}$ de distância paralelamente e externamente às parcelas, no sentido de deslocamento do vento, fios de nylon de $2 \mathrm{~mm}$ de diâmetro (ORGANIZAÇÃO INTERNACIONAL DE NORMALIZAÇÃO, 2005) e com comprimento de $4 \mathrm{~m}$, a $2 \mathrm{~m}$ de altura. Após a aplicação, os fios foram recolhidos, acondicionados em sacos plásticos e levados ao laboratório para determinação do ingrediente ativo. Eles foram lavados com um volume de $25 \mathrm{~mL}$ de álcool metílico P.A., para extração e posterior quantificação do produto presente.

Para o depósito nas plantas infestantes, procedeu-se, então, à divisão do depósito total pela massa da amostra de remoção, obtendo-se a quantidade em $\mathrm{mg} \mathrm{kg}^{-1}$ de massa úmida. Para perda para o solo e deriva, procedeu-se à divisão do depósito total pela área de remoção, obtendo-se a quantidade em $\mu \mathrm{g} \mathrm{cm}^{-2}$.

No estudo de deposição, perdas para o solo e deriva por meio da quantificação do traçador, a amostragem foi realizada de forma semelhante à anterior, tomando-se o cuidado, neste caso, de adicionar água às amostras. Após a aplicação, recolheu-se todo o material separadamente: 
plantas, lâminas de vidro e fios de nylon. Foram, então, colocados em sacos plásticos, adicionando-se $200 \mathrm{~mL}$ de água destilada às plantas e $20 \mathrm{~mL}$ às lâminas e fios. Esses sacos foram fechados, agitados por $30 \mathrm{~s}$ e acondicionados em recipientes providos de isolamento térmico e luminoso para o transporte até o laboratório. Posteriormente, foi realizada a quantificação da coloração por absorbância em $630 \mathrm{~nm}$ (faixa de detecção do corante azul utilizado), com o uso de espectrofotômetro (fotômetro fotoelétrico, Biospectro SP22), com lâmpada de tungstênio-halogênio, conforme metodologia apresentada por Palladini et al. (2005). De acordo com Pinto et al. (2007), o traçador Azul Brilhante é estável por um período de $5 \mathrm{~h}$ de exposição solar.

Com o uso da curva de calibração, obtida por meio de soluções-padrão de corante, os dados de absorbância foram transformados em concentração. A curva padrão teve como intervalo de concentração 0,50 e $50,00 \mathrm{mg} \mathrm{L}^{-1}$. O coeficiente de correlação da curva foi de 0,99 .

De posse da concentração inicial da calda e do volume de diluição das amostras, determinou-se a massa de corante retida no alvo. Para o depósito nas plantas infetantes, procedeu-se, então, à divisão do depósito total pela massa seca da amostra de remoção, obtendo-se, assim, a quantidade, em $\mathrm{mg} \mathrm{kg}^{-1}$, de massa seca. As plantas foram secas em estufa, a $65^{\circ} \mathrm{C}$, por $72 \mathrm{~h}$. Para perda para o solo e deriva, procedeu-se à divisão do depósito total pela área de remoção, obtendo-se a quantidade em $\mu \mathrm{g} \mathrm{cm}^{-2}$.

A aplicação foi realizada quando as plantas infestantes encontravam-se em estádio de pós-emergência tardia. As condições ambientais no momento da aplicação foram monitoradas por meio de um termo-higro-anemômetro digital: temperatura do ar entre 25 e $27{ }^{\circ} \mathrm{C}$, umidade relativa entre $68 \%$ e $72 \%$ e velocidade do vento entre 8 e $10 \mathrm{~km} \mathrm{~h}^{-1}$.

As principais plantas infestantes na área experimental foram: Acanthospermum hispidum (carrapicho de carneiro), Ageratum conyzoides (mentrasto), Amaranthus deflexus (caruru), Commelina benghalensis (trapoeraba), Raphanus raphanistrum (nabiça) e Chamaesyce hirta (erva de santa luzia).

$\mathrm{Na}$ análise dos dados, inicialmente foram aplicados os testes de Lilliefors e Bartlett para verificar a normalidade dos erros e a homogeneidade das variâncias. Os dados de deposição e perdas para o solo foram submetidos à análise de variância e, quando pertinente, as médias comparadas pelo teste de Tukey. Em seguida, foi realizada a análise das correlações entre os dados obtidos com a espectrofotometria e a cromatografia, por meio do coeficiente de correlação de Pearson. Foi utilizado o teste t-Student para análise deste coeficiente. Consideraram-se estatisticamente significativas as diferenças com $\mathrm{p}<0,05$.

\section{Resultados e discussão}

Os valores de massa do traçador encontrados nas folhas das plantas infestantes encontram-se na Tabela 2. Por meio da análise de variância, observou-se que não houve efeito significativo para interação entre pontas e volumes, bem como, para essas variáveis individualizadas.

A diminuição do volume de calda na aplicação não causou diferença significativa na cobertura das folhas das plantas infestantes. Menores volumes de calda proporcionam maior capacidade operacional dos equipamentos de pulverização, o que tende a reduzir os custos e aumentar o aproveitamento de boas condições climáticas. Com relação às pontas, o uso de gotas muito grossas (ponta de jato plano defletor com indução de ar) também não resultou em menor deposição, mostrando que seu uso pode ser feito em situações climáticas mais adversas ou em casos em que se deseje minimizar ao máximo o risco de deriva; contudo, mais estudos são

Tabela 2 - Massa de traçador retida na folhagem das plantas infestantes (mg de corante $\mathrm{kg}^{-1}$ ), após a aplicação do herbicida com diferentes pontas de pulverização, em dois volumes de aplicação, empregando a metodologia baseada na espectrofotometria

\begin{tabular}{|c|c|c|c|}
\hline \multirow{3}{*}{ Ponta } & \multicolumn{3}{|c|}{ Massa de traçador na folhagem (mg de corante $\left.\mathrm{kg}^{-1}\right)$} \\
\hline & \multicolumn{2}{|c|}{ Volume de aplicação $\left(\mathrm{L} \mathrm{ha}^{-1}\right)$} & \multirow{2}{*}{ Média } \\
\hline & 80 & 130 & \\
\hline Jato plano duplo de pré-orifício & 380,37 & 371,00 & 375,69 \\
\hline Jato plano defletor & 351,28 & 360,92 & 356,10 \\
\hline Jato plano defletor com indução de ar & 280,17 & 301,90 & 291,04 \\
\hline Média & 337,27 & 344,61 & \\
\hline CV (\%): 28,89 & & & \\
\hline
\end{tabular}

Valor F (Pontas x Volume): 1,124 ${ }^{\text {ns; }}$ Valor F (Pontas): 0,546 ${ }^{\text {ns; }}$ Valor F (Volume): 0,033 ${ }^{\text {ns; }}$ ns Não significativo, a 0,05 
necessários tendo em vista as limitações metodológicas apresentadas por Souza et al. (2007).

Segundo esses autores, as plantas infestantes são expostas à pulverização por um tempo extremamente curto, o que, somado a fatores como oscilações e altura da barra, vento, tamanho de gota e estádio de desenvolvimento, implica em grande variabilidade dos depósitos unitários obtidos, dificultando a diferenciação de tratamentos. O ideal seria estudar cada planta e não uma população, de forma a minimizar este problema. Contudo, para análise cromatográfica, este método é inviável economicamente, devido ao elevado número de amostras.

Na Tabela 3, estão apresentados os valores de massa de traçador direcionada ao solo após a aplicação do herbicida. Nota-se que a interação entre pontas e volumes não foi significativa, indicando que não há dependência entre os fatores. Contudo, o efeito isolado das pontas foi significativo.

A ponta de jato plano duplo de pré-orifício promoveu menores perdas de calda para o solo, enquanto que a ponta de jato plano defletor com indução de ar resultou em maiores perdas para o solo. Provavelmente, isso ocorreu em função dos espectros de gotas dessas pontas: gotas muito grossas tendem a promover perdas para o solo ao colidir com o alvo.

Com relação aos volumes de aplicação, não foi encontrada diferença. Vale ressaltar que os dois volumes utilizados estão abaixo dos volumes comumente empregados em campo (em geral próximo a $150 \mathrm{~L} \mathrm{ha}^{-1}$, dependendo da região analisada).

Com relação à deriva, usando as metodologias empregadas neste trabalho, tanto baseadas na espectrofotometria, quanto na cromatografia, a mesma não foi detectada. Destaca-se que a cromatografia é atualmente o método mais sensível para análise de resíduos de produtos fitossanitários, o que indica a pequena magnitude do fenômeno nas aplicações realizadas.
Apesar da deriva ainda ser considerada um dos maiores problemas da agricultura, nota-se que a mesma pode ser minimizada. Possivelmente, isso ocorreu em razão da aplicação ter sido realizada em condições adequadas de vento e em virtude do uso de gotas médias, grossas e muito grossas. Cunha et al. (2003), avaliando estratégias para o controle de deriva, afirmam que as pontas que produzem gotas grossas permitem redução da deriva, diminuindo o arrastamento de partículas e diminuindo significativamente o número de gotas fora da área-alvo.

$\mathrm{Na}$ Tabela 4, estão apresentadas as médias da massa de 2,4-D Amina retida na folhagem das plantas infestantes, empregandoametodologiabaseadana cromatografialíquida. A interação entre pontas e volumes não foi significativa, contudo o efeito individual de pontas e volumes foi significativo. Comparando-se os volumes de aplicação, observou-se que o menor volume de aplicação $\left(80 \mathrm{~L} \mathrm{ha}^{-1}\right)$ produziu melhor deposição na folhagem das plantas infestantes.

Tomazela etal.(2006), utilizando a ponta de jato plano XR 8001, também verificaram que a redução do volume da calda promoveu incrementos significativos na porcentagem de depósitos nas plantas de Brachiaria plantaginea. Contudo, Rodrigues et al. (2010), comparando os volumes de 100 e $200 \mathrm{~L} \mathrm{ha}^{-1}$, encontraram maiores depósitos do traçador Azul Brilhante em plantas de Commelina benghalensis com o maior volume. Uma possível explicação para esta diferença pode estar associada aos diferentes padrões de cera sobre a epiderme, pois eles determinam os diferentes graus de molhabilidade da superfície das folhas.

As pontas avaliadas promoveram diferenças na deposição. A ponta de jato plano duplo de pré-orifício, com tamanho de gotas médias, gerou maior deposição $(43,73 \mathrm{mg}$ de 2,4-D Amina $\mathrm{kg}^{-1}$ ) nas plantas infestantes, quando comparada com a de jato plano defletor com indução de ar, com tamanho de gotas muito grossas, porém não se diferenciou da ponta de jato plano defletor, com tamanho de gotas grossas.

Tabela 3 - Massa de traçador retida na placa junto ao solo ( $\mu \mathrm{g}$ de corante $\mathrm{cm}^{-2}$ ), após a aplicação do herbicida com diferentes pontas de pulverização, em dois volumes de aplicação, empregando a metodologia baseada na espectrofotometria

\begin{tabular}{llll}
\hline \multirow{2}{*}{ Ponta } & \multicolumn{2}{c}{ Massa de traçador junto ao solo $\left(\mu \mathrm{g}\right.$ de corante $\left.\mathrm{cm}^{-2}\right)$} \\
\cline { 2 - 3 } & \multicolumn{2}{c}{ Volume de aplicação $\left(\mathrm{L} \mathrm{ha}^{-1}\right)$} & \multirow{2}{*}{ Média } \\
\cline { 2 - 3 } & 80 & 130 & $0,57 \mathrm{~b}$ \\
\hline Jato plano duplo de pré-orifício & 0,51 & 0,64 & $0,75 \mathrm{ab}$ \\
Jato plano defletor & 0,74 & 0,75 & $0,98 \mathrm{a}$ \\
Jato plano defletor com indução de ar & 0,96 & 1,00 & \\
Média & $0,74 \mathrm{~A}$ & $0,80 \mathrm{~A}$ & \\
\hline
\end{tabular}

CV (\%): 26,29

Médias seguidas por letras distintas minúsculas, na coluna, e maiúsculas, na linha, diferem entre si, pelo teste de Tukey, a 0,05; Valor F (Pontas x Volume): $0,192^{\text {ns; }}$, Valor F (Pontas): 8,103**; Valor F (Volume): 0,557 ${ }^{\text {ns. ns }}$ Não significativo, a 0,05; ** Significativo, a 0,01 
Tabela 4 - Massa de 2,4-D Amina retida na folhagem das plantas infestantes (mg de 2,4-D kg-1), após a aplicação do herbicida com diferentes pontas de pulverização, em dois volumes de aplicação, empregando a metodologia baseada na cromatografia líquida

\begin{tabular}{llcc}
\hline \multirow{2}{*}{ Ponta } & \multicolumn{2}{c}{ Massa de 2,4-D Amina na folhagem $(\mathrm{mg}$ de 2,4-D kg-1) } \\
\cline { 2 - 3 } & \multicolumn{2}{c}{ Volume de aplicação $\left(\mathrm{L} \mathrm{ha}{ }^{-1}\right)$} & Média \\
\cline { 2 - 3 } & 80 & 130 & $43,73 \mathrm{a}$ \\
\hline Jato plano duplo de pré-orifício & 45,08 & 42,39 & $42,96 \mathrm{ab}$ \\
Jato plano defletor & 44,87 & 41,05 & $41,13 \mathrm{~b}$ \\
Jato plano defletor com indução de ar & 44,63 & 37,62 & \\
Média & $44,86 \mathrm{~A}$ & $40,35 \mathrm{~B}$ & \\
\hline
\end{tabular}

CV (\%): 4,37

Médias seguidas por letras distintas minúsculas, na coluna, e maiúsculas, na linha, diferem entre si, pelo teste de Tukey, a 0,05; Valor $\mathrm{F}$ (Pontas $\mathrm{x}$ Volume): 2,898 ${ }^{\text {ns }}$, Valor F (Pontas): 4,115*; Valor F (Volume): 35,092**; ns Não significativo, a 0,05; ** Significativo, a 0,01; * Significativo, a 0,05

Na Tabela 5, observa-se a massa de 2,4-D Amina retida na placa junto ao solo. A interação entre pontas e volume de aplicação foi significativa. Balan et al. (2006), avaliando depósito e perdas em sistema de pulverização com turboatomizador em videira, também comentam que há relação entre o tamanho de gota e o volume de calda, quando se avaliam perdas.

O volume de $130 \mathrm{~L} \mathrm{ha}^{-1}$ proporcionou maiores perdas para o solo em todas as pontas, quando comparado ao de $80 \mathrm{~L} \mathrm{ha}^{-1}$. Com esse volume, a ponta de jato plano duplo com pré-orificio levou à menor perda e a de jato plano defletor, com indução de ar, à maior. As gotas muito grossas têm maior peso e, por isso, maior dificuldade de retenção na folhagem, tendo como destino final, muitas vezes, o solo. Para o volume de $130 \mathrm{~L} \mathrm{ha}^{-1}$, a ponta de jato plano defletor com indução de ar também ocasionou maior perda, porém não se diferenciou da ponta de jato plano defletor.
Nos últimos anos, o uso de pontas com indução de ar tem crescido muito pelo potencial de redução de deriva (Zhu et al., 2004). No entanto, em alvos com pequeno índice de área foliar, podem comprometer a cobertura das plantas e promover maior aumento no potencial de escorrimento e perdas para o solo, em razão de as gotas serem de maior tamanho.

Comparando as duas metodologias empregadas, nota-se que os resultados da espectrofotometria levaram a um coeficiente de variação superior à cromatografia. Como consequência, não permitiu a diferenciação dos tratamentos quanto à deposição nas plantas infestantes. $\mathrm{O}$ aumento do número de repetições poderia minimizar esse problema. A cromatografia levou a uma distinção mais clara, permitindo conclusões mais precisas. Souza et al. (2007) comentam sobre a dificuldade de se avaliar depósitos em plantas infestantes, em virtude da desuniformidade de um processo de pulverização realizado em condições de campo.

Tabela 5 - Massa de 2,4-D Amina retida na placa junto ao solo ( $\mu \mathrm{g}$ de 2,4-D cm²), após a aplicação do herbicida com diferentes pontas de pulverização, em dois volumes de aplicação, empregando a metodologia baseada na cromatografia líquida

\begin{tabular}{llll}
\hline & \multicolumn{2}{c}{ Massa de 2,4-D Amina junto ao solo $\left(\mu \mathrm{g}\right.$ de 2,4-D cm $\left.\mathrm{cm}^{-2}\right)$} \\
\cline { 2 - 3 } & \multicolumn{2}{c}{ Polume de aplicação $\left(\mathrm{L} \mathrm{ha}{ }^{-1}\right)$} & Média \\
\cline { 2 - 3 } & 80 & 130 & 1,02 \\
\hline Jato plano duplo de pré-orifício & $0,99 \mathrm{cB}$ & $1,05 \mathrm{bA}$ & 1,26 \\
Jato plano defletor & $1,16 \mathrm{bB}$ & $1,36 \mathrm{aA}$ & 1,32 \\
Jato plano defletor com indução de ar & $1,22 \mathrm{aB}$ & $1,41 \mathrm{aA}$ & \\
Média & 1,12 & 1,27 & \\
\hline
\end{tabular}

CV (\%): 2,57

Médias seguidas por letras distintas minúsculas, nas colunas, e maiúsculas, nas linhas, diferem entre si, pelo teste de Tukey, a 0,05; Valor F (Pontas x Volume): 12,318**; Valor F (Pontas): 202,457**; Valor F (Volume): 133,380**; ns Não significativo, a 0,05; ** Significativo, a 0,01 
A análise cromatográfica tem como vantagem o fato de analisar diretamente o ingrediente ativo em questão, estando menos sujeitas a erros. Já segundo Palladini, Raetano e Velini (2005), o estudo da deposição com o uso de traçadores, como Azul Brilhante, tem-se demonstrado vantajoso devido sua estabilidade na luz solar e por não serem absorvidos pelas folhas, permitindo, assim, determinações quantitativas e qualitativas. Contudo, a espectrofotometria se baseia em uma avaliação indireta.

Com relação à perda de calda para o solo, a tendência dos resultados foi semelhante nas duas metodologias, embora o resultado da categorização da análise estatística tenha sido diferente. Ambos indicaram maior perda de produto com o emprego das pontas de jato plano defletor com indução de ar, e menor com as de jato plano duplo de pré-orifício.

Segundo Smelt et al. (1993), a utilização do próprio ingrediente ativo para estudo de deposição gera custos elevados e necessita de equipamentos sofisticados para as análises e de pessoas treinadas para o trabalho. Desta forma, o uso de corantes como traçadores é atrativo pela facilidade de remoção diretamente das folhas ou de alvos coletores. Esses autores compararam o depósito do traçador Brilhante Sulfoflavina com o próprio produto fitossanitário (Captan), detectados por fluorimetria e cromatografia gasosa, em aplicações em macieira. As diferenças constatadas entre os depósitos foram pequenas, permitindo concluir que o uso do corante foi uma alternativa útil e econômica para estudos de deposição.

Possivelmente, a melhor correlação entre os estudos com o ingrediente ativo e o traçador, no trabalho de Smelt et al, (1993), deve-se ao fato de se ter empregado um traçador fluorescente. A fluorimetria apresenta sensibilidade e precisão superiores à espectrofotometria. Como desvantagem, tem-se a fotodegradação que deve ser monitorada.

Com relação à análise de correlação (FIG. 1), observa-se que essa foi estatisticamente significativa entre a espectrofotometria e a cromatografia para deposição na placa junto ao solo, não sendo observado valor significativo para deposição na folhagem. De acordo com a classificação de Davis (1971), a correlação entre os dados de deposição na placa junto ao solo pode ser classificada como substancial, indicando uma associação entre os aspectos relacionados. Contudo, na folhagem o grau de relação entre as variáveis foi baixo.

As amostras utilizadas para a análise de deposição na folhagem foram diferentes para as duas metodologias, isto é, situavam-se na mesma parcela experimental, porém, após o lançamento do quadrado de madeira, coletava-se uma primeira amostra, lançava-se novamente e coletavase a próxima. Isto pode ter contribuído para a baixa correlação entre os dados de deposição na folhagem, visto
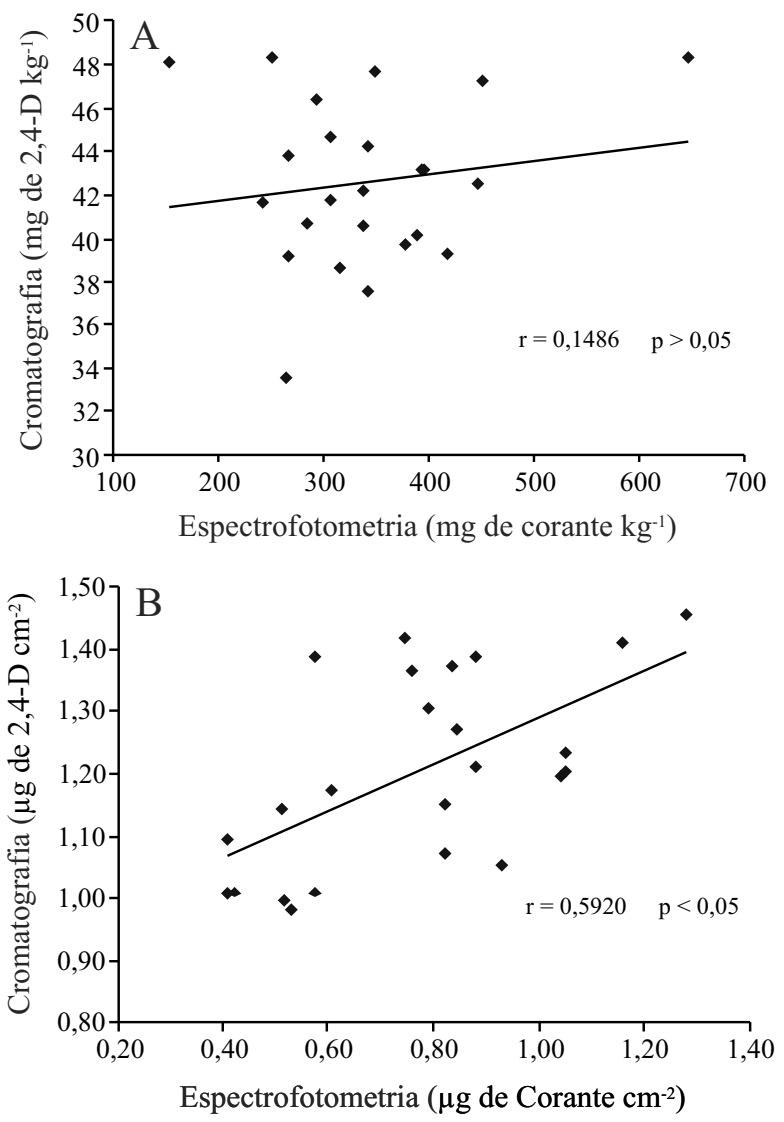

Figura 1 - Características gráficas da análise de correlação entre os dados de deposição na folhagem das plantas infestantes (A) e na placa junto ao solo (B) obtidos com a espectrofotometria e a cromatografia

que há uma variabilidade florística dentro das parcelas, o que pode levar a plantas presentes nas amostras com distintos graus de molhabilidade.

Outro aspecto ligado à espectrofotometria para estudo de deposição em folhagem é que outros compostos, com leitura em comprimentos de onda próximos ao utilizado, que não o traçador, podem influenciar nas leituras de absorbância. Um exemplo é a clorofila e impurezas presentes nas folhas. Para minimizar esse problema, as folhas foram agitadas imediatamente após a coleta e, em seguida, foi retirada uma alíquota para quantificação do traçador, evitando degradação do tecido vegetal. Contudo, um método mais apurado de separação de impurezas poderá reduzir estes problemas.

A presença de contaminantes nas placas de vidro (alvo artificial) é menor em comparação às folhas (alvo natural), em virtude do reduzido tempo de exposição às condições de campo, o que também pode ter contribuído 
com a maior correlação dos resultados com o emprego de traçador e ingrediente ativo nas análises junto ao solo. Contudo, sempre que possível deve-se dar preferência aos alvos naturais, em virtude da maior representatividade dos dados (KOCH; KNEWITZ, 2006).

\section{Conclusões}

1. Pontas que produzem gotas grossas podem ser utilizadas na dessecação de plantas infestantes com o herbicida 2,4-D, sem comprometer a cobertura do alvo. Pontas de jato plano defletor com indução de ar (gotas extremamente grossas) promoveram maior perda de herbicida para o solo;

2. Houve baixa correlação entre os dados de deposição na folhagem das plantas infestantes obtidos com a espectrofotometria e a cromatografia líquida, utilizando a metodologia de amostragem empregada. Quantoà deposição na placa junto ao solo, a correlação foi significativa;

3. Não foi possível detectar perdas por exoderiva pelas metodologias empregadas.

\section{Agradecimentos}

Ao $\mathrm{CNPq}$ e à Fapemig pelo suporte financeiro parcial, que permitiu o desenvolvimento deste trabalho de pesquisa. À Syngenta pela concessão da área de estudo.

\section{Referências}

BALAN, M. G.; SAAB, O. J. G. A.; SILVA, C. G. Depósito e perdas em sistema de pulverização com turboatomizador em videira. Engenharia Agrícola, v. 26, n. 02, p. 470-477, 2006.

BOLLER, W.; MACHRY, M. Efeito da pressão de trabalho e de modelos de pontas de pulverização sobre a eficiência de herbicida de contato em soja. Engenharia Agrícola, v. 27, n. 03, p. 722-727, 2007.

CUNHA, J. P. A. R. et al. Avaliação de estratégias para a redução da deriva de agrotóxicos em pulverizações hidráulicas. Planta Daninha, v. 21, n. 02, p. 325-332, 2003.

CUNHA, J. P. A. R. Simulação da deriva de agrotóxicos em diferentes métodos de aplicação. Revista Ciência Agronômica, v. 39 , n. 04 , p. $487-493,2008$

CUNHA, J. P. A. R. et al. Aplicação aérea e terrestre de fungicida para o controle de doenças do milho. Revista Ciência Agronômica, v. 41, n. 03, p. 366-372, 2010.

DAVIS, J. A. Elementary survey analysis. Englewood: Prentice-Hall, 1971. 206 p.
HEWITT, A. J. Tracer and collector systems for field deposition research. Aspects of Applied Biology, v. 99, n. 01, p. 283-289, 2010.

KOCH, H.; KNEWITZ, H. Methodology and sampling technique of spray deposit and distribution measurement in orchards. Nachrichtenblatt des Deutschen Pflanzenschutzdienstes, v. 58, n. 01, p. 6-9, 2006.

NUYTTENS, D. et al. Effect of nozzle type, size and pressure on spray droplet characteristics. Biosystems Engineering, v. 97, n. 03, p. 333-345, 2007.

NUYTTENS, D. et al. Experimental study of factors influencing the risk of drift from field sprayers: part 1: meteorological conditions. Aspects of Applied Biology, v. 77, n. 01, p. 01-08, 2006.

ORGANIZAÇÃO INTERNACIONAL DE NORMALIZAÇÃO. ISO/FDIS 22866: Equipment for crop protection: methods for field measurement of spray drift. Geneva, 2005. $22 \mathrm{p}$.

PALLADINI, L. A.; RAETANO, C. G.; VELINI, E. D. Choice of tracers for the evaluation of spray deposits. Scientia Agrícola, v. 62 , n. 05 , p. $440-445,2005$.

PINTO, J. R. et al. Estabilidade à exposição solar dos traçantes azul brilhante e amarelo tartrasina utilizados em estudos de deposição de pulverização. Revista Brasileira de Agrociência, v. 13, n. 01, p. 105-107, 2007.

RODRIGUES, A. C. P. et al. Avaliação qualitativa e quantitativa na deposição de calda de pulverização em Commelina benghalensis. Planta Daninha, v. 28, n. 02, p. 421-428, 2010.

SMELT, J. H.; SMIDT, R. A.; HUIJSMANS, J. F. M. Comparison of spray deposition on apple leaves of captan and the dye brilliant sulfoflavine. In: SYMPOSIUM INTERNATIONAL SUR LES TECHNIQUES D'APPLICATION DES PRODUITS PHYTOSANITAIRES, 2., 1993, Strasbourg. Annales... Strasbourg: British Crop Protection Council, 1993. p. 191-197.

SOUZA, R. T.; VELINI, E. D.; PALLADINI, L. A. Aspectos metodológicos para análise de depósitos de pulverizações pela determinação dos depósitos pontuais. Planta Daninha, v. 25, n. 01, p. 195-202, 2007.

SUGUISAWA, J. M. et al. Qualidade de aplicação de herbicida em lavoura de trigo. Engenharia Agrícola, v. 27, p. 41-47, 2007. Número especial.

TOMAZELA, M. S. et al. Avaliação da deposição da calda de pulverização em função da densidade populacional de Brachiaria plantaginea, do volume e do ângulo de aplicação. Planta Daninha, v. 24, n. 01, p. 183-189, 2006.

TSAI, M. et al. The Washington aerial spray drift study: modeling pesticide spray drift deposition from an aerial application. Atmospheric Environment, v. 39, n. 33, p. 6194-6203, 2005.

VIANA, R. G. et al. Características técnicas de pontas de pulverização LA-1JC e SR-1. Planta Daninha, v. 25, n. 01, p. 211-218, 2007.

ZHU, H. et al. Spray penetration into peanut canopies with hydraulic nozzle tips. Biosystems Engineering, v. 87, n. 03, p. 275-283, 2004. 